\title{
O testamento vital à luz do ordenamento jurídico brasileiro e o princípio pro homine
}

\author{
The living will in the light of the Brazilian legal system and the pro homine principle \\ El testamento vital a la luz del ordenamiento jurídico brasileño y el principio pro homine
}

Meiriany Arruda Lima ${ }^{1}$

RESUMO. Objetivo: $O$ artigo teve por escopo analisar se o Testamento Vital, previsto na Resolução no 1.995 do Conselho Federal de Medicina, publicada em 31 de dezembro de 2012, atende ao princípio pro homine. Metodologia: Tratou-se de pesquisa qualitativa, descritiva e analítica, com utilização de material bibliográfico, legislativo e jurídico. Resultados: Apesar da existência do Testamento Vital não há, até o momento, legislação específica sobre o tema; a discussão sobre as diretivas antecipadas de vontade no cenário nacional tem-se mostrado tímidas; o princípio pro homine representa uma maneira de salvaguardar a aplicabilidade da Resolução oㅡ 1.995/2012 do Conselho Federal de Medicina. Conclusão: O Testamento Vital previsto na Resolução no 1.995/2012 do Conselho Federal de Medicina atende ao melhor interesse do paciente, mesmo não havendo legislação específica sobre o tema, o que, por seu turno, precisa ser sanado com brevidade, uma vez que o direito à vida está diretamente implicado nesta discussão, e o desenvolvimento técnico científico tem proporcionado formas artificiais de prolongar a vida ou como alguns preferem, adiar a morte.

Palavras-chaves: Normas jurídicas. Direito a morrer. Legislação Sanitária.

ABSTRACT. Objective: The purpose of this article was to analyze whether the living will provided for in Resolution 1.995 of the Federal Council of Medicine published on December 31, 2012 takes account of the pro homine principle. Methodology: Qualitative, descriptive and analytical research, for which bibliographic, legislative and legal material was used. Results: Despite the existence of the Living Will, there is no specific legislation on the topic addressed in this study; the discussion about the early directives of will on the national scene has been timid; the pro homine principle represents a way of safeguarding the applicability of the 1.995 Federal Medical Council Resolution. Conclusion: The living will provided for by the Resolution 1.995/2102 of the Federal Council of Medicine serves the best interest of the patient, even though there is no specific legislation on the subject in question, which in turn needs to be remedied shortly, since the right to life is directly involved in this discussion and that technical. scientific development has provided artificial ways of prolonging life or, as some prefer, to postpone death.

Keywords: Enacted Statutes. Right to Die. Health Legislation.

RESUMEN. Objetivo: El presente artículo tuvo por objeto analizar si el Voluntad en Vida previsto en la Resolución 1.995 del Consejo Federal de Medicina editada a 31 de diciembre

\footnotetext{
${ }^{1}$ Advogada e especialista em Direito Público. Servidora Pública, Hospital Universitário de Brasília. Mestranda em Bioética na Universidade de Brasília-UnB.E-mail: meirianyarrudalima@gmail.com.
} 
de 2012 atiende al principio pro homine. Metodología: Se trató de investigación cualitativa, descriptiva y analítica, para lo cual se utilizó material bibliográfico, legislativo y jurídico. Resultados: A pesar de la existencia del Voluntad en Vida no existe hasta el momento legislación específica sobre el tema abordado en este trabajo; la discusión sobre las directivas anticipadas de voluntad en el escenario nacional se ha mostrada tímida; el principio pro homine representa una manera de salvaguardar la aplicabilidad de la Resolución 1.995 / 2012 del Consejo Federal de Medicina. Conclusión: El Voluntad en Vida previsto en la Resolución 1.995 / 2102 del Consejo Federal de Medicina atiende al mejor interés del paciente, aunque no haya legislación específica sobre el tema en cuestión, lo que a su vez debe ser subsanado a la brevedad, ya que el derecho a la vida está directamente implicado en esta discusión y que el desarrollo técnico científico ha proporcionado formas artificiales de prolongar la vida o como algunos prefieren posponer la muerte.

Palabras-clave: Normas Jurídicas. Derecho a Morir. Legislación Sanitaria.

\section{Introdução}

A necessidade de um instrumento que assegure validade acerca das diretivas antecipadas de vontade do paciente terminal, surge no amago da discussão sobre o direito à autodeterminação.

O direito em decidir sobre como ou o que fazer ou não fazer com o paciente, quando este não mais puder expressar sua vontade, é fundamental para garantia da dignidade da pessoa humana. Neste cenário surge o testamento vital, que por seu turno vem a ser instrumento de validade à vontade futura do paciente terminal ou portador de doença fora de proposta terapêutica de cura.

Originalmente proposto pela Sociedade Americana para o Direito de Eutanásia, o testamento vital surge nos Estados Unidos da América em 1967, seu objetivo era registrar a vontade dos pacientes em interromper a terapêutica de prolongamento artificial da vida. $\mathrm{Na}$ Espanha, em 2002, após ratificação da Convenção de Direitos Humanos e Biomedicina, foi aprovada a Lei Federal n 41/2002 normatizando as diretivas antecipadas/ testamento vital, por eles chamada de instruções prévias. Na Itália e Argentina, a judicialização do direito à suspenção e a tratamentos que prolonguem a vida motivou a discussão sobre o testamento vital. Enquanto que, no Brasil, os direitos dos pacientes terminais vêm sendo discutido de maneira tímida (1).

Segundo Pessini, validar o testamento vital representa a humanização da morte, pois ninguém deve ser obrigado a morrer diferente do que viveu. Ou seja, deve-se respeitar os valores e crenças do indivíduo, que nortearam toda sua jornada, e não respeitar o direito de decidir sobre sua finitude representa uma violação sem precedentes ao ser humano (2). 
Atualmente, existem meios artificiais de prolongação da vida ou "sobrevida", uma vez que, os avanços biotecnológicos e biocientíficos têm logrado êxito na busca em perpetuar a existência humana. Entretanto, faz-se necessário avaliar os limites terapêuticos partindo de uma visão bioética, para que não ocorram violações aos direitos humanos (1) (3).

O fato de existirem recursos terapêuticos para prolongar a vida, requer ser sopesado a beneficência desses meios frente ao quadro do paciente, uma vez que a ciência existe para o bem do homem e não o inverso (3).

O regramento jurídico nacional resguarda o direito à vida enquanto direito fundamental e não determina que deva o paciente terminal ou qualquer indivíduo deva submeter-se a tratamentos que prolonguem a vida de forma contrária ao que foi a sua existência.

A morte digna envolve respeito à autonomia do indivíduo, respeito às diferenças culturais e acatar as decisões tomadas pelo paciente visando agir em conformidade com sua consciência, desde que, tais decisões não limitem o direito de terceiros. Ao escolher a suspenção dos tratamentos terapêuticos, o indivíduo opta por não ser levado a uma exaustão terapêutica desmedida (4).

Respeitar a decisão dos pacientes terminais ou com doenças incuráveis de não se submeterem a tratamentos exaustivos e sem prognóstico de cura, encontra amparo no princípio da dignidade da pessoa humana. Tal princípio visa o respeito à integridade física e psíquica, condições materiais mínimas para viver, liberdade e igualdade para o ser humano (5).

Nesse contexto de discussão mundial, o Conselho Federal de Medicina publicou a Resolução $n^{\circ} 1.995 / 2012$, que dispõe sobre as diretivas antecipadas de vontade, mas que tem força obrigatória apenas entre a classe médica.

A partir de então, o testamento vital começou a ter um lugar nas abordagens da equipe multidisciplinar, que atendem a pacientes fora de cura terapêutica, ampliando a discussão na sociedade, atendendo a proposta do respeito à autonomia do paciente e preservando sua dignidade (1) (5).

A existência das lacunas legislativas nacionais e internacionais frente aos direitos humanos tornou necessária em alguns casos, à aplicabilidade principiológica a fim de decidir o caso concreto. Nesses casos, a recomendação é pela aplicabilidade do princípio pro homine, também conhecido como norma mais favorável ao indivíduo, que recomenda a 
interpretação da norma mais benéfica ao indivíduo, quando do conflito entre normas que versem sobre direitos humanos (6).

Frente ao contexto apresentado, não é levado em consideração à hierarquia da norma, mas, o seu conteúdo, privilegiando a norma mais efetiva à proteção dos direitos humanos, independendo de sua posição no ordenamento jurídico (6) (7).

Diante desse contexto, o objetivo do presente artigo foi analisar o Testamento Vital previsto na Resolução no 1.995/2012 do Conselho Federal de Medicina, à luz do ordenamento jurídico brasileiro, com a aplicação do princípio pro homine.

\section{Metodologia}

Tratou-se de pesquisa qualitativa, descritiva, analítica, legislativa e bibliográfica.

Fez-se apurada análise sobre a Resolução n 1995 de 2012 do Conselho Federal de Medicina, bem como, identificou-se as normas que autorizaram a criação do Testamento Vital no ordenamento jurídico pátrio, bem como, foi realizado levantamento de obras literárias que discorressem sobre o Princípio pro homine.

Foram realizadas buscas nos sítios: LILACS, RENTEV, SciELO e Google scholar, que resultaram no retorno dos artigos, dissertações e teses de domínio público, datados entre 2008 a 2017.

Os descritores utilizados foram: "living wills, normas jurídicas, direito a morrer com dignidade, legislação sanitária".

O critério de exclusão utilizado foi não contribuir com informações relevantes sobre princípio pro homine e/ou testamento vital.

O suporte bibliográfico incluiu ainda obras de doutrinadores contemporâneos que discorrem sobre testamento vital, direito do paciente, dignidade humana e princípio pro homine, que foram identificadas após pesquisa in loco, no acervo bibliográfico do Supremo Tribunal Federal, Fundação Oswaldo Cruz -Fiocruz/Brasília e Senado Federal.

As pesquisas legislativa e jurídica ocorreram nas bases LexML do Senado Federal, bem como, nos sítios do Supremo Tribunal Federal. Os levantamentos foram feitos entre os meses de julho e outubro de 2017.

Após levantamento, foi realizada a leitura do material bibliográfico, em busca dos conceitos sobre princípio pro homine, Testamento Vital e informações sobre a criação e relevância da Resolução n 1.995/2012 do Conselho Federal de Medicina. 
A forma de análise do material bibliográfico foi a interpretação hermenêutica, a fim de verificar se o conceito de Testamento Vital, previsto na Resolução no 1.995/2012 do Conselho Federal de Medicina, atende ao disposto no conceito do princípio pro homine, e neste sentido foram descritas as características do Testamento Vital, previstas na Resolução $\mathrm{n}^{\circ}$ 1.995/2012 do Conselho Federal de Medicina. A avaliação legislativa ocorreu via apreciação dos potenciais efeitos resultantes da aplicação da Resolução n 1.995/2012 do Conselho Federal de Medicina.

Em um total de 33 produtos levantados, foram selecionadas 24 amostras para construção textual, estás por sua vez citadas direta ou indiretamente no corpo do texto, enquanto 9 amostras foram utilizadas como suporte de leitura para compreensão do tema estudado.

As amostras utilizadas para construção dos resultados e discussão seguem discriminadas nos quadros 1 e 2 .

\section{Resultados e discussão}

Da revisão da literatura, foram encontrados escassa produção sobre a área do testamento vital. A produção intelectual sobre a temática ainda é acanhada em língua portuguesa. Os achados foram:

Quadro 1 - Textos sobre o Testamento Vital, publicados em língua portuguesa.

\begin{tabular}{|c|c|}
\hline Autor & Tema \\
\hline Penalva & $\begin{array}{l}\text { Terminalidade e autonomia: uma abordagem do testamento vital no direito } \\
\text { brasileiro }\end{array}$ \\
\hline Pessini & Distanásia: até quando prolongar a vida? \\
\hline Villas-Bôas & Um direito fundamental à ortotanásia \\
\hline Telles & A morte digna sob a ótica judicial \\
\hline Junior & Direito fundamental à vida: pilar do estado democrático de direito \\
\hline $\begin{array}{l}\text { Gomes \& } \\
\text { Mazzuoli }\end{array}$ & $\begin{array}{l}\text { Constituição brasileira e os tratados de direitos humanos: conflito e critério de } \\
\text { solucão }\end{array}$ \\
\hline $\begin{array}{l}\text { Piovesan } \\
\text { Gomes }\end{array}$ & $\begin{array}{l}\text { Temas de direitos humano } \\
\text { Direito dos Direitos humanos e a regra interpretativa "pro homine" }\end{array}$ \\
\hline Alves & $\begin{array}{l}\text { A evolução histórica dos tratados internacionais sobre Direitos humanos e sua } \\
\text { hierarquia normativa no ordenamento jurídico interno }\end{array}$ \\
\hline
\end{tabular}




\begin{tabular}{|c|c|}
\hline $\begin{array}{l}\text { Trindade Apud } \\
\text { Piovesan }\end{array}$ & $\begin{array}{l}\text { El derecho internacional de los derechos humanos en el siglo XXI In Direitos } \\
\text { Humanos e o Direito Constitucional Internacional }\end{array}$ \\
\hline Henderson & $\begin{array}{l}\text { Los tratados internacionales de derechos humanos em el orden interno: La } \\
\text { importancia del principio pro homine }\end{array}$ \\
\hline Figueiredo & $\begin{array}{l}\text { Da hierarquia dos tratados de direitos humanos no ordenamento jurídico } \\
\text { brasileiro }\end{array}$ \\
\hline Gomes & $\begin{array}{l}\text { Direito internacional dos Direitos humanos-validade e operacionalidade do } \\
\text { princípio pro homine }\end{array}$ \\
\hline Sarlet & Integração dos tratados de Direitos Humanos no ordenamento jurídico \\
\hline Penalva & $\begin{array}{l}\text { Distorções acerca do testamento vital no Brasil (ou o porquê é necessário } \\
\text { falar sobre uma declaração prévia de vontade do paciente terminal) }\end{array}$ \\
\hline Nunes & Testamento Vital. Nascer e Crescer \\
\hline Penalva & Sobre os três anos da Resolução do CFM n 1.995/2012 \\
\hline Pereira & O direito à plenitude da vida e a possibilidade de uma morte digna \\
\hline
\end{tabular}

Fonte: elaborado pela autora a partir do material bibliográfico encontrado.

O trabalho igualmente localizou a legislação brasileira sobre a temática do Testamento Vital.

Quadro 2 - Legislação sobre o Testamento Vital brasileira.

\begin{tabular}{|c|c|}
\hline Norma & Tema \\
\hline $\begin{array}{l}\text { Resolução } 1.995 \text { de } 2012 \text { do } \\
\text { Conselho Federal de Medicina }\end{array}$ & $\begin{array}{l}\text { Dispõe sobre as diretivas antecipadas de vontade/testamento } \\
\text { vital. }\end{array}$ \\
\hline $\begin{array}{l}\text { Convenção Interamericana de } \\
\text { Direitos Humanos - artigo } 29 .\end{array}$ & [...]normas de interpretação dos tratados de direitos humanos. \\
\hline $\begin{array}{l}\text { Convenção de Viena. Decreto } \\
\text { № } 7.030 \text {, de } 14 \text { de dezembro } \\
\text { de } 2009 \text { - artigo } 27 .\end{array}$ & $\begin{array}{l}\text { "Uma parte não pode invocar as disposições de seu direito } \\
\text { interno para justificar o inadimplemento de um tratado". }\end{array}$ \\
\hline $\begin{array}{l}\text { Código Civil- Lei } \mathrm{n}^{\circ} \\
10.406 / 2002 \text { - artigo } 1.858 .\end{array}$ & $\begin{array}{l}\text { Forma prevista no ordenamento jurídico brasileiro para validar } \\
\text { o testamento. }\end{array}$ \\
\hline $\begin{array}{l}\text { Constituição Federal de } 1988 \text { - } \\
\text { artigo } 5^{\circ} \text {, inciso II. }\end{array}$ & $\begin{array}{l}\text { [...] "ninguém será obrigado a fazer ou deixar de fazer alguma } \\
\text { coisa senão em virtude de lei." }\end{array}$ \\
\hline $\begin{array}{l}\text { Conselho Nacional de Justiça } \\
- \text { Enunciado } \mathrm{n}^{\circ} 37 \text {. }\end{array}$ & $\begin{array}{l}\text { As diretivas ou declarações antecipadas de vontade que } \\
\text { especificam os tratamentos médicos que o declarante deseja }\end{array}$ \\
\hline
\end{tabular}


ou não se submeter quando incapacitado de expressar-se autonomamente[...]

Fonte: elaborado pela autora a partir da pesquisa legislativa.

\section{Princípio Pro homine}

O princípio pro homine, conhecido como norma mais favorável ao indivíduo, pode ser descrito como a interpretação da norma mais benéfica ao sujeito de direito. A respeito dos direitos humanos, o Direito Internacional e o Direito interno deverão se retroalimentar para que seja considera a primazia da pessoa humana quando da aplicação normativa (7) (8).

A aplicação da norma mais benéfica ou menos restritiva ao indivíduo surge no pós Segunda Guerra (1939 - 1945), momento em que o mundo vivenciava uma série de violações ao princípio da dignidade humana (9).

Nesse contexto, o princípio pro homine tem por premissa garantir o princípio da dignidade da pessoa humana, não considerando hierarquização normativa, outrossim, elevando a valoração dos direitos humanos como meio de garantir que não aconteçam os crimes de lesa humanidade outrora praticados.

Na visão de Mazzuoli (6), quando da antinomia das normas deveria haver um "diálogo de fontes". Em outras palavras, ao invés de uma norma rechaçar a outra, deve-se pensar em como alcançar a melhor forma de integração entre normas, no afã de garantir os direitos fundamentais humanos. A partir desta perspectiva, o autor defende que a aplicação do princípio pro homine não está restrita a resolver conflitos entre normas internacionaisnacionais, podendo sua aplicabilidade ser factível diante da antinomia entre nacionaisnacionais.

[...] ao permitir fluxos internormativos recíprocos que prestigiam "la norma más protectora", dotada de maior peso valorativo, referida sistemática seria igualmente aplicável em caso de antinomias horizontais, no concurso entre normas com o mesmo nível hierárquico (6).

No mesmo sentido, Trindade (10) defende que os Estados signatários de tratados de direitos humanos assumam deliberadamente a responsabilidade em assegurar o princípio da dignidade humana, não podendo, portanto, alegar impedimentos normativos, constitucionais ou não, como forma de barreira a não observância dos preceitos fundamentais que norteiam a garantia da dignidade humana. 
A Convenção Americana sobre Direitos Humanos de 1948, em seu artigo 29, versa sobre as normas de interpretação dos tratados de direitos humanos (11).

O Pacto Internacional de Direitos Civis e Políticos descreve o princípio pro homine como forma de interpretação mais benéfica sobre as normativas que envolvem direitos humanos:

Pacto Internacional de Derechos Civiles y Políticos (16/12/1966), artículo 5: "Ninguna disposición del presente Pacto podrá ser interpretada em el sentido de conceder derecho alguno a uno Estado, grupo o individuo para emprender actividades o realizar actos encaminados a la destrucción de cualquiera de los derechos y libertades reconocidos em el Pacto o a su limitación en mayor medida que la prevista en él. No podrá admitir se restricción o menos cabo de ninguno de los derechos humanos fundamentales reconocidos o vigentes en un Estado Parte en virtud de leyes, convenciones, reglamentos o costumbres, so pretexto de que el presente Pacto no los reconoceolos reconoce en menor grado". (12)

O princípio pro homine pode ser constatado também no artigo 27 da Convenção de Viena de 1969 disposto da seguinte maneira: "Uma parte não pode invocar as disposições de seu direito interno para justificar o inadimplemento de um tratado" (13).

Pode-se observar que o princípio pro homine surgiu no cenário normativo internacional como garantidor da efetividade da aplicabilidade ou interpretação extensiva da norma mais benéfica ao indivíduo, evitando desta forma um retrocesso normativo que pudesse estar respaldado na hierarquia das normas (6).

\section{O princípio pro homine no ordenamento jurídico brasileiro}

O princípio pro homine não está declarado expressamente no ordenamento jurídico brasileiro, e sim, em tratados internacionais que versam sobre direitos humanos os quais foram incorporados ao direito interno. Em países como México e Equador, o referido princípio é previsto em seu texto constitucional (14).

A incorporação de atos ou tratados internacionais no ordenamento jurídico brasileiro observa três fases distintas: 1) O uso da competência privativa do Presidente da República para celebrar atos e tratados internacionais (art. 84, VIII, CF/88); 2) Avaliação e aprovação do Congresso Nacional, dos atos e tratados internacionais "que possam acarretar encargos ou compromissos gravosos ao patrimônio nacional" (art. 49, I, CF/88). Tal ato se materializa com a expedição de decreto legislativo; 3). Por fim, tem-se a edição de decreto presidencial 
dos tratados já ratificados pelo Congresso Nacional. Apenas após a publicação do decreto presidencial a norma jurídica adquire executoriedade (15).

A discussão travada na doutrina jurídica é a posição desses atos ou tratados internacionais na pirâmide hierárquica das normas, especialmente quando versem sobre direitos humanos.

Sarlet (16) assevera que os tratados que versem sobre Direitos humanos podem ser recepcionados de duas maneiras no ordenamento brasileiro. A recepção com status de Emenda Constitucional, desde que, respeitado o disposto no parágrafo $3^{\circ}$, artigo $5^{\circ}$ da Constituição Federal de 1988, ou seja, serem aprovados em cada Casa do Congresso Nacional, em dois turnos, por três quintos dos votos dos respectivos membros. Outra forma de recepção dar-se-á quando ratificado pelo Brasil e recepcionado por Decreto Legislativo com aprovação por maioria simples, neste caso, terá status de lei ordinária, ambas admitidas pelo Superior Tribunal Federal.

Menciona ainda que a interpretação da norma mais favorável a proteção dos Direitos humanos requer, afastar-se da prática da hierarquização das normas e considerar a análise do caso concreto, buscando o diálogo entre as fontes do Direito como forma de garantir o que for mais benéfico e amplo na proteção dos direitos humanos (16).

Acerca do princípio pro homine Gomes, descreve que:

[...] a Constituição Federal de 1988, os Tratados de Direitos Humanos e a legislação ordinária se retroalimentam e se complementam, ou seja, no plano material não há que se falar (ou é irrelevante falar) em hierarquia entre as normas de Direitos Humanos: por força do princípio ou regra pro homine sempre será aplicável (no caso concreto) a que mais amplia o gozo de um direito ou de uma liberdade ou de uma garantia (8).

Gomes (8) explica que após evoluções normativas e principiológicas têm surgido uma nova pirâmide normativa, com a seguinte disposição:

Formal: na base encontraremos as normas legais, no meio os Direitos Internacionais dos direitos humanos recepcionados por maioria simples, e tem status supralegal e no topo teremos a Constituição Federal e os tratados que versem sobre direitos humanos, recepcionados conforme rito previsto no artigo $5^{\circ}$, $\S 3^{\circ}$ da Constituição Federal de 1988, e confere a estes força de emenda constitucional (8).

Material: os tratados que versem sobre direitos humanos, a Constituição Federal e as leis ordinárias retroalimentar-se-ão, ou seja, são complementares entre si, não havendo 
sobreposição ou hierarquia normativa. Neste plano encontra-se o princípio pro homine, pois será aplicada a regra que atenda ao caso concreto de forma a preservar ou ampliar os direitos humanos sem preponderar o status normativo (8).

\section{Testamento Vital}

O testamento vital surge enquanto instrumento que viabiliza o reconhecimento das disposições antecipadas de vontade dos pacientes terminais, que escolhem deliberar sobre tratamentos terapêuticos aos quais devam ser submetidos ou não quando não estiverem mais em condições de decidir. Ou seja, este instrumento busca preservar a autonomia e dignidade humana, através da garantia ao direito à autodeterminação do paciente, que por seu turno deverá ser respeitado por seus familiares, bem como, pela equipe médica e hospitalar (1).

No Brasil, a expressão testamento vital surge como tradução do termo living will, adotado pelos Estados Unidos da América, em 1967, como documento de cuidados antecipados, em que o paciente poderia registrar que fossem dispensados tratamentos com o fito de prolongar a vida. Em 1991, após decisão do judiciário, foi aprovada a lei federal Patient Self Determination Act, que legitimou o direito à autodeterminação dos pacientes, outrora proposto pela Sociedade Americana para o Direito a Eutanásia (1).

Todavia, no Brasil, o termo foi questionado devido a possibilidade de confusão com a figura jurídica do testamento civil, previsto no direito de sucessões. Foi proposto a adoção do termo "declaração prévia de vontade do paciente terminal", que vem sendo aceito pelos bioeticistas (17).

Assim, o objetivo do testamento vital é permitir ao ser humano dispor previamente, sobre procedimentos a serem adotados ainda em vida, quando em condições terminais não possa mais expressar sua vontade. Não se confunde com o testamento civil, pois não abarca decisões sobre disposições de bens, porém, existem algumas semelhanças, quais sejam: ser ato unilateral, dispor de capacidade civil, formal, revogável e personalíssimo (1).

No Brasil, inexiste norma jurídica específica que trate do tema e sim uma construção interpretativa de inúmeros dispositivos legais que fornecem sustentação jurídico-legal para a aplicação de tal instrumento. 
A Constituição Brasileira apresenta como um dos fundamentos da nossa República a dignidade da pessoa humana (art. 1ํ, III). Dispõe ainda, em seu art. $5^{\circ}$, III, a proibição ao tratamento desumano (1).

O Código Civil, por sua vez, assevera em seu artigo 15, que: "Ninguém pode ser constrangido a submeter-se, com risco de vida, a tratamento médico ou a intervenção cirúrgica" (18).

Com os avanços tecnológicos e terapêuticos, muitas vezes, um paciente terminal é levado à exaustão terapêutica sem que haja expectativa de cura. Por isso, a necessidade de poder decidir de forma autônoma sobre os procedimentos aos quais deseja ou não ser submetido de modo a não colidir com seus valores morais, espirituais e mentais, bem como salvaguardar a dignidade deste paciente deve ser considerado.

Ainda assim, não se pode olvidar da necessidade de obedecer a alguns requisitos formais, para que tenha validade quais sejam: competência para decidir de forma autônoma sobre as propostas terapêuticas (o paciente terminal deverá ser capaz de compreender os desdobramentos que podem ocorrer a partir de suas decisões, bem como, deve ter caráter voluntário) (19).

Não existe legislação específica que regulamente a forma a ser adotada para elaboração do Testamento Vital. Contudo, a orientação descrita na Resolução n¹.995/2012 do Conselho Federal de Medicina limita-se ao registro no prontuário médico sobre as diretivas antecipadas de vontade que forem comunicadas diretamente ao médico, por se tratar de tema tão controverso, na tentativa em resguardar os direitos tanto do paciente quanto do médico. A doutrina estabeleceu alguns requisitos de validade, tais como (19):

a) Restrito às pessoas com capacidade civil, maiores de 18 anos, em pleno gozo de suas faculdades mentais;

b) Deverá ser apresentado por profissional médico familiarizado com o tema;

c) Eficácia na conduta médica e não apenas meramente informativo;

d) Formulário padronizado para viabilizar as diretivas;

e) Poderá ser revogado a qualquer instante;

f) Deverá ser renovado a cada 5 anos;

g) Registro cartorário ou perante funcionário da RENTEV (Registro Nacional de Testamento Vital); 
h) Elaboração no ambiente do sistema de saúde de Registro Nacional de Testamento Vital, para que aja celeridade no acesso pelos profissionais de saúde.

Importa esclarecer que, apesar da orientação doutrinária quanto à forma de validade do testamento vital, o ordenamento jurídico brasileiro deixa claro que, em razão do princípio da legalidade, ninguém será constrangido a nada senão em detrimento de previsão legal. Portanto, a validade do testamento vital esta adstrita apenas a forma prevista na Resolução № 1.995/2012 do Conselho Federal de Medicina (20).

Sendo à vida um bem jurídico tutelado pelo Estado e considerado indisponível, viver com dignidade implica ter seus valores éticos e morais respeitados desde o nascimento até a sua morte, e por representar a dignidade da pessoa humana uma máxima no ordenamento jurídico, faz-se necessário rever a relação com a finitude da vida humana.

\section{Resolução do Conselho Federal de Medicina n 1.995/2012}

A dignidade da pessoa humana é considerada pelo ordenamento jurídico pátrio uma máxima. Portanto, a inexistência de legislação específica sobre testamento vital não deve ser vista como impedimento para o exercício da autodeterminação do paciente que faz jus a tal benesse.

Pensando em como minimizar as consequências deste vazio legislativo, por termo a adoção de condutas terapêuticas desmedidas, disciplinarem a conduta do profissional médico frente ao direito à autodeterminação do paciente como forma de respeito e preservação da dignidade da pessoa humana, foi publicada em 31 de agosto de 2012 a Resolução n 1.995 do Conselho Federal de Medicina (21).

A edição desta Resolução está relacionada diretamente a primazia do indivíduo, ampliando a aplicação da norma mais benéfica ao ser humano, por meio do reconhecimento da autonomia do paciente na tomada das decisões sobre as propostas terapêuticas a ele apresentadas e facultando que o mesmo autodetermine o que ou como deverá ser feito quando não mais puder expressar sua vontade.

A Resolução n 1.995/2012 do CFM surge em meio as discussões envolvendo diretivas antecipadas de vontade e/ou testamento vital. Este ato normativo dispõe sobre a suspensão de procedimentos e tratamentos médicos e terapêuticos que tenham como finalidade prolongar a vida de pacientes fora de propostas terapêuticas de cura, sem deixar de lado o direito do paciente em ter assegurado controle da dor e qualidade de vida (21). 
Segundo a Resolução, esta manifestação pode ser apresentada de duas formas, pessoalmente ou por meio de seu representante legalmente constituído, para ser praticada quando o paciente não mais estiver em condições de expressar sua vontade.

A partir da edição desta Resolução do Conselho Federal de Medicina, o testamento vital começou a ter um lugar consolidado nas abordagens da equipe multidisciplinar que atendem à pacientes fora de cura terapêutica, ampliando a discussão junto às categorias multiprofissionais e a sociedade, bem como, buscando atender à autonomia do paciente (21).

A Resolução do Conselho Federal de Medicina $n^{\circ}$ 1.995/2012 teve sua constitucionalidade contestada pelo Ministério Público Federal do Estado do Goiás em sede de ação civil pública, no ano de 2013 (ACP № 1039-86.2013.4.01.3500). Os motivos relatados pelo autor da ação abordavam a insegurança jurídica, o fato dos familiares não poderem invalidar a decisão do paciente, a capacidade do paciente, o tempo de validade do instrumento e o fato do testamento vital ficar acostado no prontuário do paciente. Por considerar entrave o prontuário médico de documento de acesso restrito, o Ministério Público Federal questionou a competência normativa do Conselho Federal de Medicina e postulou pela inconstitucionalidade. Que fosse declarada a ilegalidade do ato e suspensa sua aplicação em todo território nacional (22).

Os pedidos foram rejeitados liminarmente e foi interposto agravo de instrumento $\mathrm{n}^{\circ}$ 0019373-95.2013.4.01.0000, que por seu turno, ficou concluso no gabinete do doutor desembargador relator por aproximadamente um ano. O processo em primeira instância não estava suspenso, fazendo com que o juiz responsável prolatasse sentença publicada em 02 de abril de 2014, reconhecendo a constitucionalidade da Resolução $n^{\circ} 1.995 / 2012$ do Conselho Federal de Medicina. Na visão do MM. Juiz, a Resolução está posta enquanto a norma na relação ética profissional atende ao princípio da dignidade da pessoa humana e permite ao paciente exercer sua autonomia (22).

Posteriormente, o Conselho Nacional de Justiça, durante a realização da I Jornada de Direito da Saúde, em 28 de maio de 2014, apresentou o enunciado que trata sobre o tema:

Enunciado $\mathrm{n}^{\circ} 37$ - As diretivas ou declarações antecipadas de vontade que especificam os tratamentos médicos que o declarante deseja ou não se submeter quando incapacitado de expressar-se autonomamente, devem ser feitas preferencialmente por escrito, por instrumento particular, com duas testemunhas, ou público, sem 
prejuízo de outras formas inequívocas de manifestação admitidas em direito (23).

Essas decisões trouxeram uma maior segurança jurídica à utilização das diretivas ou declarações antecipadas de vontade, tanto para os pacientes, como para os profissionais de saúde (23). Ademais, representa um avanço jurídico, social e normativo no Brasil, em tema tão polêmico e tão delicado.

Viver e morrer com dignidade remete às reflexões acerca de tolerância, solidariedade, cuidado, responsabilidade, compromisso e convivência humana, pois, o princípio da dignidade humana encontra-se incurso em duas atribuições uma defensiva que vela pela não violação da dignidade e outra prestacional que busca proteger e promover a dignidade da pessoa humana (24).

\section{Considerações Finais}

A partir das evoluções biotecnológicas surgiram conflitos envolvendo o prolongamento da vida ou as tentativas em adiar a morte. Para alguns, não utilizar os recursos postos para prolongar a vida representou morrer com dignidade, enquanto, para outros significou uma morte prematura.

Pensar a morte não é algo que a sociedade aceite com naturalidade. Nesse sentido, a Resolução do Conselho Federal de Medicina $n^{\circ}$ 1.995/2012 surge para tentar compor este cenário, garantindo o direito e o respeito às decisões de pacientes submetidos a tratamentos terapêuticos - por vezes desnecessários, atrelados a uma relação médica paternalista, ou relação de despreparo da família no enfrentamento da morte.

Resgatar a autonomia do paciente em autodeterminar-se é garantir sua dignidade quando do fim de sua vida, sendo o pluralismo jurídico e a dignidade da pessoa humana pilares estruturantes do Estado Democrático de Direito. É importante que o ser humano enquanto indivíduo decida o seu processo de morte, por envolver decisões personalíssimas que jamais deveriam ser tomadas por familiares, médicos ou o próprio Estado, uma vez que configuraria um retrocesso o fato do indivíduo não poder dispor sobre a própria vida ou assegurar o exercício da sua autonomia sobre o próprio corpo.

Portanto, se o Testamento Vital tiver sido elaborado no momento em que a pessoa era capaz de discernir sobre sua vontade, possuía consciência de seus atos e precedia a um 
estado de terminalidade, a família e os profissionais devem reconhecer e respeitar a autodeterminação deste paciente.

Ressalta-se também a validade e eficácia do Testamento Vital à luz do ordenamento jurídico por encontrar-se pareado com o princípio da dignidade humana e o exercício da autonomia, mesmo sendo necessária uma regulamentação normativa que garanta o cumprimento e aceite do testamento vital de forma erga omnes.

Cabe rememorar que o princípio da dignidade humana é inerente ao indivíduo tendo, portanto, um caráter absoluto enquanto direito, e que por seu turno o reconhecimento por parte do Estado erigindo a princípio garantido constitucionalmente ratifica a ulterioridade principiológica da dignidade humana.

Não foi a pretensão de este trabalho exaurir a discussão proposta, senão contribuir para construção de uma proposta que aborde o direito à vida, sobretudo considerando a morte enquanto dignidade que permeia as decisões de vida em toda sua complexidade. Ademais, também demonstrar a importância do testamento vital no cenário nacional enquanto garantia do direito à autodeterminação preservando a autonomia do paciente, principalmente quando se tratar de terminalidade e finitude.

\section{Referências}

1. Penalva LD, Teixeira AC. Terminalidade e autonomia: uma abordagem do testamento vital no direito brasileiro. In: Pereira TS, Menezes RA, Barboza HH. Vida, morte e dignidade humana. Rio de Janeiro: Gz, 2010.

2. Pessini L. Distanásia: até quando prolongar a vida? São Paulo: Loyola, 2001.

3. Villas-Bôas ME. Um direito fundamental à ortotanásia. In: Pereira TS, Menezes RA, Barboza HH. Vida, morte e dignidade humana. Rio de Janeiro: Gz, 2010.

4. Telles COM, Coltro ACM. A morte digna sob a ótica judicial. In: Pereira TS, Menezes RA, Barboza HH. Vida, morte e dignidade humana. Rio de Janeiro: Gz, 2010.

5. Junior PSML, Oliveira MMP. Direito fundamental à vida: pilar do estado democrático de direito In: Pereira TS, Menezes RA, Barboza HH. Vida, morte e dignidade humana. Rio de Janeiro: Gz, 2010.

6. Gomes LF, Mazzuoli VO. Constituição brasileira e os tratados de direitos humanos: conflito e critério de solução. Disponível em: https://lfg.jusbrasil.com.br/noticias/1110801/constituicao-brasileira-e-os-tratados-dedireitos-humanos-conflito-e-criterio-de-solucao [Acesso em 15.jul.2017] 
7. Piovesan F. Temas de direitos humanos. São Paulo: Max Limonad, 2003.

8. Gomes LF. Direito dos Direitos humanos e a regra interpretativa "pro homine". Revista do Programa de Mestrado em Ciência Jurídica da Fundinopi. Anual 2007 (7):197202.

Disponível em: http://seer.uenp.edu.br/index.php/argumenta/article/view/80/80 [Acesso em 23. jul.2017]

9. Alves FG, Rodrigues ACP. A evolução histórica dos tratados internacionais sobre Direitos humanos e sua hierarquia normativa no ordenamento jurídico interno. Disponível em:

https://seminario2015.ccsa.ufrn.br/assets//upload/papers/f8fc6b322baffc31f5b7f6a4771c53f e.pdf [Acesso em 15.set.2017]

10. Trindade AAC. El derecho internacional de los derechos humanos en el siglo XXI. Editorial Juridica de Chile, Santiago: 2006, p. 41 apud Piovesan F. Direitos Humanos e o Direito Constitucional Internacional. São Paulo: Editora Saraiva, 2015.

11. Comissão Interamericana de Direitos Humanos. Convenção Americana Sobre Direitos Humanos. Disponível em:

https://www.cidh.oas.org/basicos/portugues/c.convencao americana.htm [Acesso em 18.set. 2017]

12. Henderson H. Los tratados internacionales de derechos humanos en el orden interno: la importancia del principio pro homine. Corte Interamericana de Derechos Humanos. 2004; 39:71-94. Disponível em: http://www.corteidh.or.cr/tablas/R06729-3.pdf [Acesso em: 18.set.2017]

13. Brasil. Decreto no 7.030, de 14 de dezembro de 2009. Promulga a Convenção de Viena sobre o Direito dos Tratados, Disponível em: http://www.planalto.gov.br/ccivil 03/ ato2007-2010/2009/decreto/d7030.htm [Acesso em 18.set.2017]

14. Figueiredo JVM. Da hierarquia dos tratados de direitos humanos no ordenamento jurídico brasileiro. Disponível em: http://www.conteudojuridico.com.br/artigo,da-hierarquiados-tratados-de-direitos-humanos-no-ordenamento-juridico-brasileiro,56319.html [Acesso em 18.set.2017]

15. Gomes LF. Direito internacional dos Direitos humanos-validade e operacionalidade do princípio pro homine. Revista Jurídica do Ministério Público de Minas Gerais. Disponível em:

https://aplicacao.mpmg.mp.br/xmlui/bitstream/handle/123456789/119/Direito\%20internacio nal\%20direitos\%20humanos Gomes.pdf?sequence=1 [Acesso em 10.out.2017]

16. Sarlet I. Integração dos tratados de Direitos Humanos no ordenamento jurídico. Coluna Conjur, 2015. Disponível em: http://www.conjur.com.br/2015-mar-27/direitos- 
fundamentais-integracao-tratados-direitos-humanos-ordenamento-juridico [Acesso em 20. set.2017]

17. Penalva LD. Distorções acerca do testamento vital no Brasil (ou o porquê é necessário falar sobre uma declaração prévia de vontade do paciente terminal). Revista de Bioética y Derecho. 2013; 28(05):61-71. Disponível em: http://www.bioeticayderecho.ub.edu/[Acesso em 15.ago.2017]

18. Brasil. Código Civil. Disponível em: https://www.jusbrasil.com.br/topicos/10729769/artigo-15-da-lei-n-10406-de-10-de-janeirode-2002 [Acesso em 19.set.2017]

19. Nunes R. Testamento Vital. Nascer e Crescer. Revista de Pediatria do Centro Hospitalar do Porto. 2012; 21(4): 250-255. Disponível em: http://repositorio.chporto.pt/bitstream/10400.16/1421/1/v21n1a10.pdf [Acesso em 5.set.2017]

20. Brasil. Constituição Federal de 1988. Disponível em: https://www2.senado.leg.br/bdsf/bitstream/handle/id/518231/CF88 Livro EC91 2016.pdf?s equence $=1$ ? concurso=CFS $\% 202 \% 202018$ [Acesso em 5.set.2017]

21. Penalva LD. Sobre os três anos da Resolução do Conselho Federal de Medicina $n^{\circ}$ 1.995/2012. Disponível em: http://testamentovital.com.br/sobre-os-tres-anos-da-resolucaocfm-19952012/ [Acesso em 2.outubro.2017]

22. Brasil. Justiça Federal do Estado de Goiás. Ação Civil Pública n¹0398.2013.4.01.3500/7100 Disponível em: http://testamentovital.com.br/wpcontent/uploads/2014/07/senten\%C3\%A7a-ACP-testamento-vital.pdf [Acesso em 21.ago.2017]

23. Brasil. Conselho Nacional de Justiça. I Jornada de Direito da Saúde. Disponível em: http://www.cnj.jus.br/images/ENUNCIADOS APROVADOS NA JORNADA DE DIREITO DA SAUDE \%20PLENRIA 155514 r.pdf [Acesso em 2.out.2017]

24. Pereira TS. O direito à plenitude da vida e a possibilidade de uma morte digna. In: Pereira TS, Menezes RA, Barboza HH. Vida, morte e dignidade humana. Rio de Janeiro: Gz, 2010.

Como citar este artigo:

Lima MA. O testamento vital à luz do ordenamento jurídico brasileiro e o princípio pro homine. Revista Cadernos Ibero-Americanos de Direito Sanitário. 2018 jan./mar, 7(1):12-28. 